\title{
Preoperative neutrophil:lymphocyte and platelet:lymphocyte ratios predict endometrial cancer survival
}

\author{
M Cummings ${ }^{1}$, L Merone ${ }^{1}$, C Keeble ${ }^{2}$, L Burland ${ }^{1}$, M Grzelinski ${ }^{1}$, K Sutton $^{1}$, N Begum ${ }^{1}$, A Thacoor ${ }^{1}$, B Green ${ }^{1}$, \\ J Sarveswaran ${ }^{1}$, R Hutson ${ }^{1}$ and N M Orsi ${ }^{\star, 1}$ \\ ${ }^{1}$ Women's Health Research Group, Leeds Institute of Cancer and Pathology, Wellcome Trust Brenner Building, St James's \\ University Hospital, Beckett Street, Leeds LS9 7TF, UK and ${ }^{2}$ Leeds Institute of Cardiovascular and Metabolic Medicine, Division of \\ Epidemiology and Biostatistics, University of Leeds, Leeds LS2 9JT, UK
}

Background: Variations in systemic inflammatory response biomarker levels have been associated with adverse clinical outcome in various malignancies. This study determined the prognostic significance of preoperative neutrophil:lymphocyte (NLR), platelet:lymphocyte (PLR) and monocyte:lymphocyte (MLR) ratios in endometrial cancer.

Methods: Clinicopathological and 5-year follow-up data were obtained for a retrospective series of surgically treated endometrial cancer patients $(n=605)$. Prognostic significance was determined for overall (OS) and cancer-specific survival (CSS) using Cox proportional hazards models and Kaplan-Meier analysis. Receiver-operator characteristic and log-rank functions were used to optimise cut-offs. NLR, PLR and MLR associations with clinicopathological variables were determined using non-parametric tests.

Results: Applying cut-offs of $\geqslant 2.4$ (NLR), $\geqslant 240$ (PLR) and $\geqslant 0.19$ (MLR), NLR and PLR (but not MLR) had independent prognostic significance. Combining NLR and PLR scores stratified patients into low (NLR-low and PLR-low), intermediate (NLR-high or PLRhigh) and high risk (NLR-high and PLR-high) groups: multivariable hazard ratio (HR) 2.51; $P<0.001$ (OS); HR 2.26; $P<0.01$ (CSS) for high vs low risk patients. Increased NLR and PLR were most strongly associated with advanced stage $(P<0.001)$, whereas increased MLR was strongly associated with older age $(P<0.001)$.

Conclusion: Both NLR and PLR are independent prognostic indicators for endometrial cancer, which can be combined to provide additional patient stratification.

Endometrial cancer is the commonest gynaecological malignancy in the Western world, accounting for $6.1 \%$ of all cancers in European women (Ferlay et al, 2013). Almost 8500 cases are diagnosed annually in the UK, leading to over 2000 deaths (Cancer Research UK cancer statistics, 2014). Moreover, the incidence of endometrial cancer in the UK has increased by $43 \%$ in 15 years since 1993-1995, attributable in part to factors resulting in unopposed oestrogen exposure such as obesity, certain hormone replacement therapies and the use of tamoxifen to treat breast cancer. This rise has also been accompanied by a $14 \%$ increase in the number of deaths due to endometrial cancer over the same time period (National Cancer Intelligence Network, 2013).
Endometrial cancers are primarily adenocarcinomas and have been traditionally categorised into types I and II on the basis of aetiology, molecular characteristics and clinical behaviour (Bohkman, 1983). Type I endometrial cancer (endometrioid endometrial cancer, EEC) is the commonest, accounting for $\sim 80 \%$ of sporadic cases. It typically develops in peri-menopausal women in a background of premalignant hyperplasia and is usually oestrogen/progesterone receptor positive. By contrast, type II endometrial cancers (serous and clear cell carcinomas) usually arise in a background of atrophic (postmenopausal) endometrium, are high-grade, hormone receptor negative and typically follow an aggressive clinical course (Dedes et al, 2011). While early stage, low

*Correspondence: Dr NM Orsi; E-mail: n.m.orsi@leeds.ac.uk

Received 16 January 2015; revised 16 April 2015; accepted 6 May 2015; published online 16 June 2015

(c) 2015 Cancer Research UK. All rights reserved 0007-0920/15 
grade EEC is classically managed by curative hysterectomy, latestage EEC/type II endometrial cancers are associated with significant mortality due to their metastatic spread outwith the uterine corpus (Dedes et al, 2011; DeLeon et al, 2014). Difficulties still exist with the type I/II classification system in terms of prognosis: there is uncertainty as to whether grade 3 EECs should be classified as type I or type II carcinomas (Boruta et al, 2004; Hamilton et al, 2006; Soslow et al, 2007; Voss et al, 2012) while the prognostic significance of tumours with mixed type I/II histology remains the subject of debate (Patsavas et al, 2011; Roelofson et al, 2012). The existence of grade 1 EECs arising in a background of atrophic endometrium also presents difficulties for this dualistic model (Geels et al, 2012). Finally, endometrial carcinosarcomas (formerly named malignant mixed Müllerian tumours) are now considered to be metaplastic carcinomas (McCluggage, 2002) which carry an exceptionally poor prognosis (Amant et al, 2005), although their clinical behaviour is to some extent dictated by the histology of their epithelial component (de Jong et al, 2011). Thus, there is an ongoing need to identify objective biomarkers, both to improve risk stratification and to guide therapeutic management.

The host response to malignant tumours is characterised by systemic inflammation, resulting in a relative thrombocytosis, neutrophilia and lymphocytopenia. Biomarkers of systemic inflammation such as elevated neutrophil:lymphocyte ratio (NLR), platelet:lymphocyte ratio (PLR) and absolute monocyte counts have shown potential for guiding the clinical management of cancer patients across a range of malignancies (Clarke et al, 2011). High preoperative NLR and PLR and, more recently, monocyte:lymphocyte ratio (MLR) have been shown to associate with adverse outcomes in a range of solid tumours (Li et al, 2013; Templeton et al, 2014a, b), although a paucity of data exist on their prognostic significance in the context of endometrial cancer. The aim of this study was therefore to investigate the prognostic significance of preoperative NLR, PLR and MLR in a large retrospective series of surgically treated endometrial cancer patients with 5-year follow-up data.

\section{MATERIALS AND METHODS}

Patients and data collection. This retrospective study examined the records of a sequential series of 733 patients with a new diagnosis of primary endometrial cancer between January 2005 and December 2007 within the North and West Yorkshire Deanery, UK. Ethical approval was obtained from Leeds East Research Ethics Committee (ref: 05/Q1107/41). Data were obtained from Patient Pathway Manager (Newsham et al, 2011) and case notes from the Yorkshire Cancer Network units. Followup was 3-monthly for the first 18 months, 6-monthly for the next 18 months, then annually until 5 years when patients were offered to be discharged back to their GP, with the option of continuing annual follow-up visits thereafter. Mobility within the region was limited as judged by the numbers seen in follow-up clinics. Patients who moved from the centre during the follow-up period were reviewed in their local regional hospital by accessing their local electronic records by one of the investigators (MG). All deaths were cross-checked against death certificates and patients were censored at end of follow-up, if death had not occurred. Patients were managed according to regional guidelines, taking into account patient performance status: the extent of surgical staging was based on preoperative histological findings and imaging, where lymphadenectomy ( \pm omental sampling and peritoneal washings) was only performed on early stage patients with Type II histology. Following post-operative staging, adjuvant combination chemotherapy (Paclitaxel + Carboplatin) was administered to patients with stage III/IV disease, followed by consolidation external beam radiotherapy (EBRT). Brachytherapy was reserved for those patients with tumour involving the cervical epithelium (if Type II) or stroma (if Type I). Type II stage I cancers were sometimes given EBRT at the discretion of the physician. A total of 128 patients were excluded; these comprised patients who were lost to follow-up $(n=7)$, those with no preoperative blood parameter data available $(n=54)$, patients that did not have a hysterectomy $(n=54)$ and patients with a diagnosis of uterine sarcoma/ unknown uterine tumour $(n=13)$. Individual Charlson scores were calculated from recorded co-morbidities (Charlson et al, 1987). Staging data were converted from the International Federation of Gynaecology and Obstetrics (FIGO) 1988 to the FIGO 2009 staging system (Creasman, 2009) according to pathology reports. Patients' full blood count data (including absolute leukocyte, neutrophil, eosinophil, basophil, monocyte, lymphocyte and platelet counts) were collected from a time frame of $<2$ weeks prior to hysterectomy and used to calculate NLR, PLR and MLR. We chose to calculate MLR, the reciprocal of the more frequently used lymphocyte:monocyte ratio (LMR), to standardise by dividing myeloid lineage counts by lymphoid lineage cell counts for all relevant variables.

Statistical analysis. Data normality was assessed using Kolmogorov-Smirnov tests and associations of NLR, MLR and PLR with other categorised clinicopathological prognostic variables were determined using either Mann-Whitney $U$-tests or KruskalWallis tests followed by post-hoc pairwise Mann-Whitney U-tests. Bonferroni's correction was applied for multiple comparisons, as appropriate. NLR, MLR and PLR correlations were performed using Spearman's rho test.

Overall (OS) and cancer-specific survival (CSS) were defined as time from diagnosis to death (all causes) and death due to endometrial cancer (where endometrial cancer was listed as a cause of death in the death certificate), respectively. In cases where endometrial cancer was not listed as a cause, deaths were censored in CSS analysis. Survival analyses on categorical variables were performed using the Kaplan-Meier method and significant differences between groups were identified using the log-rank test. Univariable and multivariable survival analyses were performed using Cox proportional hazards models. NLR, PLR and MLR cutoff optimisation was performed using the software package Cutoff Finder (Budczies et al, 2012). Two approaches were used for cut-off determination: (a) standard ROC curve analysis based on binary outcome, using Manhattan distance to calculate optimal cut-offs, and (b) fitting the Cox proportional hazards models to dichotomised NLR, PLR and MLR variables and the timedependent survival variable, whereby the optimal cut-off point gave the lowest log-rank $P$-value.

Statistical analysis was performed using $R$ (R Core Team, 2014) and IBM SPSS (Statistical Package for the Social Sciences; Version 21, Armonk, NY, USA). Missing data were handled by pairwise exclusion. All statistical tests used in this study were twosided and $P$-values of $<0.05$ were considered significant.

\section{RESULTS}

Patient characteristics. Patient demographics have been summarised in Supplementary Table 1. Median age at diagnosis was 65 years (range 28-95) and all selected patients underwent a total hysterectomy with bilateral salpingo-oophorectomy. Lymphadenectomy (pelvic/para-aortic) was performed in $71 \%$ of patients, $33 \%$ of patients received adjuvant radiotherapy and $13 \%$ of patients received adjuvant chemotherapy. The majority of patients (78\%) were diagnosed at early stage (I/II) and EEC was the predominant (77\%) histopathological subtype. Median follow-up time (reverse Kaplan-Meier method) was 81.5 months (range 58-103). 
Throughout the follow-up period there were 166 deaths, 96 of which were attributable to endometrial cancer (see Materials and Methods). The estimated cumulative 5-year survival for this patient population was $76 \pm 1.7 \%$ for OS and $84 \pm 1.5 \%$ for endometrial CSS.

Prognostic significance of preoperative blood parameters and cut-off determination. To investigate the potential prognostic significance of preoperative blood parameters, univariable Cox proportional hazards analyses were performed on continuous data, whereby each parameter was scaled to its own median value to enable cross-comparison of hazard ratios (HRs) (Supplementary Table 2). These exploratory analyses revealed leucocyte, neutrophil, lymphocyte and platelet counts to be significantly associated with survival, where increased leucocytes and neutrophils associated with worse OS and CSS, increased lymphocytes associated with better OS and CSS and increased platelets associated with worse CSS (but not OS). No significant relationships between monocyte, eosinophil or basophil counts and survival were identified. These analyses also revealed NLR, PLR and MLR ratios to be highly significantly associated with adverse outcome for both OS and CSS (all $P<0.001$ ), and to have a superior prognostic significance compared with any blood parameters not expressed as a ratio. On this basis, all three ratios were selected for further analysis.

Although an NLR cut-off of $\geqslant 5$ is commonly applied in the prognostic setting (particularly in colorectal carcinoma), its use is not universal (Templeton et al, 2014a). Cut-off PLR values used for prognostication in cancers range from 160 to 300 (Templeton et al, 2014b), and similarly, cut-off LMR values applied to nonhaematological malignancies range from 2.9 (Stotz et al, 2014a) to 5.3 ( $\mathrm{Li}$ et al, 2013). We therefore chose to perform cut-off optimisation for NLR, PLR and MLR on our study cohort. Optimised cut-offs were determined for each parameter using standard ROC curve analysis and time-dependent survival (see Materials and Methods). In ROC curve analyses, the areas under the curve (AUC) for OS were $0.616(P<0.001), 0.583$ $(P=0.002)$ and $0.592(P=0.001)$ for NLR, PLR and MLR, respectively. For CSS, respective AUC values for NLR, PLR and MLR were $0.620 \quad(P<0.001), 0.611 \quad(P=0.001)$ and 0.589 $(P=0.006)$, respectively. For NLR, a cut-off of 2.4 was found to be optimal for OS and CSS using ROC curve determination and this value also gave the lowest log-rank $P$-value $(P<0.0001)$ for time-dependent survival analysis. For PLR, cut-offs were similar using both approaches ( 240 and 250 for ROC and time-dependent survival, respectively; both $P<0.0001$ ), and a cut-off of 240 was selected to maximise the number of patients in the PLR-high group (14\%). For MLR, there was a large discrepancy between cut-offs determined by ROC curve $(0.19 ; P<0.001)$ and time-dependent survival analysis $(0.66 ; P<0.0001)$. Since the latter approach defined only $2 \%$ of the patient cohort as MLR-high, patients were dichotomised according to the ROC curve cut-off. This value (0.19) corresponds to an LMR cut-off of 5.3.

Univariable survival analysis of patients stratified according to NLR, PLR and MLR cut-offs and other prognostic parameters. Prognostic parameters for univariable analysis included age, Charlson co-morbidity index, FIGO 2009 stage, grade, histopathological subtype and the presence of lymphovascular space invasion, a known independent prognostic indicator for endometrial cancer (Briët et al, 2005). Depth of myometrial invasion, cervical involvement and lymph node status form part of the FIGO staging system and, as such, were not included as independent variables in the analysis. Patients were stratified into four age groups including two 10-year groups around the median age (65 years). All prognostic parameters except the Charlson co-morbidity index were significantly associated with OS and CSS in univariable analysis (Tables 1 and 2, respectively) and were therefore included in subsequent multivariable models.

Kaplan-Meier analysis for OS (Figure 1A-C) and CSS (Figure 2A-C) revealed that patients with high preoperative NLR, PLR or MLR (corresponding to a low LMR) had significantly worse OS and CSS. Platelet:lymphocyte ratio dichotomisation showed the greatest survival difference with a cumulative 5-year OS survival rate of $54 \%$ (PLR-high) vs $80 \%$ (PLR-low), followed by NLR (68\% high vs $86 \%$ low) and then MLR (72\% high vs $83 \%$ low).

Table 1. Overall survival of patients stratified according to
NLR, PLR and MLR cut-offs, together with other prognostic parameters

\begin{tabular}{|c|c|c|c|c|}
\hline \multirow[b]{2}{*}{ Parameter } & \multicolumn{2}{|c|}{ Univariable } & \multicolumn{2}{|c|}{ Multivariable } \\
\hline & HR $(95 \% \mathrm{Cl})$ & $P$ & $\mathrm{HR}(95 \% \mathrm{Cl})$ & $P$ \\
\hline \multicolumn{5}{|l|}{ MLR } \\
\hline $\begin{array}{l}\text { Low }(<0.19) \\
\text { High }(\geqslant 0.19)\end{array}$ & $\begin{array}{c}1 \text { (Referent) } \\
1.89(1.31-2.72)\end{array}$ & 0.001 & $\begin{array}{c}1 \text { (Referent) } \\
1.23(0.84-1.82)\end{array}$ & 0.294 \\
\hline \multicolumn{5}{|l|}{ NLR } \\
\hline $\begin{array}{l}\text { Low }(<2.4) \\
\text { High }(\geqslant 2.4)\end{array}$ & $\begin{array}{c}1 \text { (Referent) } \\
2.37(1.68-3.34)\end{array}$ & $<0.001$ & $\begin{array}{c}1 \text { (Referent) } \\
1.82(1.27-2.62)\end{array}$ & 0.001 \\
\hline \multicolumn{5}{|l|}{ PLR } \\
\hline $\begin{array}{l}\text { Low }(<240) \\
\text { High }(\geqslant 240)\end{array}$ & $\begin{array}{c}1 \text { (Referent) } \\
2.72(1.92-3.84)\end{array}$ & $<0.001$ & $\begin{array}{c}1 \text { (Referent) } \\
1.89(1.30-2.75)\end{array}$ & 0.001 \\
\hline \multicolumn{5}{|c|}{ Combined NLR + PLR } \\
\hline $\begin{array}{l}\text { NLR-low + PLR- } \\
\text { low } \\
\text { NLR-high or } \\
\text { PLR-high } \\
\text { NLR-high + PLR- } \\
\text { high }\end{array}$ & $\begin{array}{c}1 \text { (Referent) } \\
1.89(1.30-2.73) \\
3.92(2.58-5.96)\end{array}$ & $\begin{array}{l}0.001 \\
<0.001\end{array}$ & $\begin{array}{c}1 \text { (Referent) } \\
1.59(1.08-2.35) \\
2.54(1.61-4.01)\end{array}$ & $\begin{array}{l}0.018 \\
<0.001\end{array}$ \\
\hline \multicolumn{5}{|l|}{ Age (years) } \\
\hline $\begin{array}{l}<55 \\
55-64 \\
65-74 \\
\geqslant 75\end{array}$ & $\begin{array}{c}1 \text { (Referent) } \\
1.84(0.91-7.49) \\
3.44(1.75-6.75) \\
7.46(3.84-14.50)\end{array}$ & $\begin{array}{l}0.091 \\
<0.001 \\
<0.001\end{array}$ & $\begin{array}{c}1 \text { (Referent) } \\
2.72(1.28-5.78) \\
4.41(2.17-5.78) \\
7.64(3.74-15.61)\end{array}$ & $\begin{array}{l}0.009 \\
<0.001 \\
<0.001\end{array}$ \\
\hline $\begin{array}{l}\text { Charlson co- } \\
\text { morbidity index }\end{array}$ & $0.93(0.79-1.10)$ & 0.419 & - & - \\
\hline \multicolumn{5}{|c|}{ Stage (FIGO 2009) } \\
\hline $\begin{array}{l}\text { I } \\
\text { II } \\
\text { III } \\
\text { IV }\end{array}$ & $\begin{array}{c}1 \text { (Referent) } \\
1.49(0.84-2.65) \\
4.29(3.01-6.12) \\
12.66(8.03- \\
19.97) \\
\end{array}$ & $\begin{array}{l}0.169 \\
<0.001 \\
<0.001\end{array}$ & $\begin{array}{c}1 \text { (Referent) } \\
1.16(0.63-2.14) \\
2.31(1.51-3.53) \\
5.57 \text { (3.19-9.74) }\end{array}$ & $\begin{array}{l}0.633 \\
<0.001 \\
<0.001\end{array}$ \\
\hline \multicolumn{5}{|l|}{ Grade } \\
\hline $\begin{array}{l}1 \\
2 \\
3\end{array}$ & \begin{tabular}{c|}
1 (Referent) \\
$1.71(1.06-2.75)$ \\
$5.26(3.56-7.77)$
\end{tabular} & $\begin{array}{c}0.027 \\
<0.001\end{array}$ & $\begin{array}{c}1 \text { (Referent) } \\
1.38(0.83-2.29) \\
1.98(1.15-3.40)\end{array}$ & $\begin{array}{l}0.216 \\
0.014\end{array}$ \\
\hline
\end{tabular}

\section{Histopathological subtype}

\begin{tabular}{|c|c|c|c|c|}
\hline $\begin{array}{l}\text { Endometrioid } \\
\text { (EEC) }\end{array}$ & 1 (Referent) & & 1 (Referent) & \\
\hline Serous & $5.48(3.51-8.56)$ & $<0.001$ & $1.66(0.95-2.90)$ & 0.076 \\
\hline Clear cell & $8.31(4.31-16.05)$ & $<0.001$ & $1.71(0.70-4.16)$ & 0.243 \\
\hline Carcinosarcoma & $6.35(3.90-10.35)$ & $<0.001$ & $2.28(1.25-4.16)$ & 0.007 \\
\hline $\begin{array}{l}\text { Mixed } \\
(E E C+\text { non-EEC) }\end{array}$ & $2.30(1.44-3.67)$ & $<0.001$ & $1.06(0.61-1.86)$ & 0.838 \\
\hline \multicolumn{5}{|c|}{ Lymphovascular space invasion } \\
\hline Absent & 1 (Referent) & & 1 (Referent) & \\
\hline Present & $3.69(2.66-5.13)$ & $<0.001$ & $1.66(1.12-2.46)$ & 0.012 \\
\hline
\end{tabular}

Abbreviations: $\mathrm{Cl}=$ confidence interval; $\mathrm{EEC}=$ endometrioid endometrial carcinoma; $\mathrm{FIGO}=$ International Federation of Gynaecology and Obstetrics; HR = hazard ratio; MLR = monocyte:lymphocyte ratio; NLR = neutrophil:lymphocyte ratio; PLR = platelet:lymphocyte ratio. Univariable and multivariable analysis using Cox proportional hazards models. NLR, PLR, MLR and combined NLR + PLR were adjusted separately in models that all included age, stage, grade, histopathological subtype and lymphovascular space invasion. Results from the multivariable model which included combined NLR + PLR score are indicated in bold. 
Table 2. Cancer-specific survival of patients stratified according to NLR, PLR and MLR cut-offs, together with other prognostic parameters

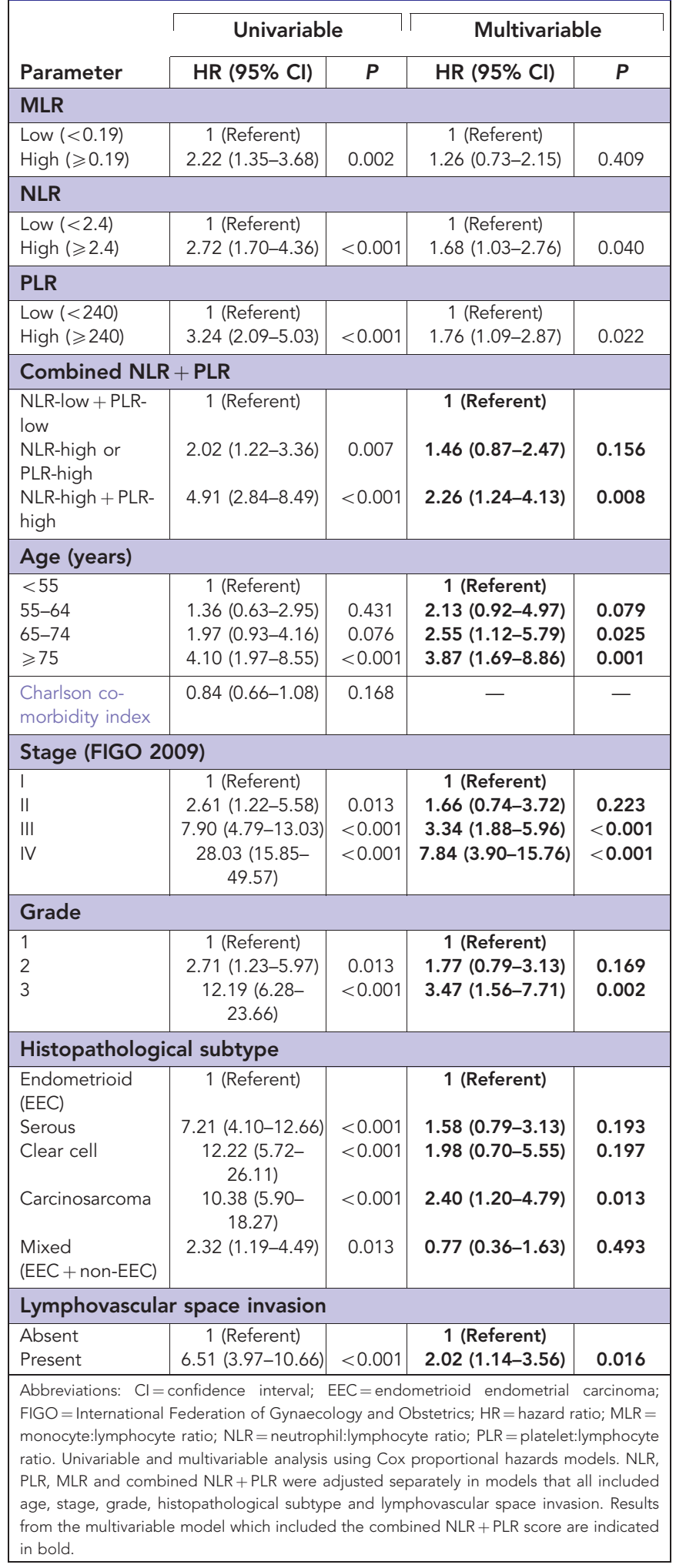

These results were echoed by CSS with estimated cumulative 5-year survival rates of $67 \%$ (PLR-high) vs $87 \%$ (PLR-low), NLR (78\% high vs $91 \%$ low) and MLR ( $81 \%$ high vs $90 \%$ low). However, the enhanced survival difference identified by PLR dichotomisation was offset by the fact that it only defined a relatively small subset of patients (14\%) as high risk (Figures 1C and 2C).
NLR and PLR have independent prognostic significance. Since NLR, PLR and MLR were strongly correlated with each other (Spearman's rho coefficients of 0.728 (NLR vs PLR), 0.682 (NLR vs MLR) and 0.583 (PLR vs MLR; all $P<0.001$ ), all three factors were adjusted separately in multivariable Cox proportional hazards models which included age, stage, grade, histopathological subtype and lymphovascular space invasion (Tables 1 and 2 for OS and CSS, respectively). Both NLR and PLR were independent prognostic factors for OS and CSS, albeit more highly significant for OS. By contrast, MLR had no independent prognostic value for either OS or CSS.

Combining NLR and PLR provides additional patient stratification. Methods to combine NLR and PLR scores to improve patient stratification in relation to clinical outcome were then investigated. Approaches such as combining the NLR and PLR values as geometric means did not identify cut-offs that performed well in multivariable analysis (data not shown). Indeed, the simplest and most effective approach was to stratify patients into three groups: (a) PLR-low and NLR-low, (b) PLR-high or NLR-high and (c) PLR-high and NLR-high (Figures 1D and 2D). These corresponded to low, intermediate and high risk groups, with estimated cumulative 5 -year OS rates of $85 \%, 76 \%$ and $54 \%$, respectively, and estimated cumulative 5-year CSS rates of $91 \%$, $83 \%$ and $67 \%$, respectively. When adjusted for other prognostic parameters (Table 1), both the high and intermediate risk groups had significantly worse OS than the low risk group. For CSS (Table 2), the difference between high and low risk groups was accentuated (compared with when simple NLR and PLR cut-offs were used to dichotomise patients), although the low and intermediate risk groups did not differ significantly from each other in the multivariable model. It is worth noting that only one patient was PLR-high and NLR-low, which might be expected given the strong positive correlation of PLR with NLR. One might therefore hypothesise that simply raising the NLR cut-off threshold would also identify this high risk group. We did indeed apply a cutoff of 5.0-which is the most widely used value in the literature, particularly in colorectal cancer (Guthrie et al, 2013a) - to our patient population but this did not perform as well as when applying our optimised cut-offs for either OS (multivariable HR for NLR $\geqslant 5: 1.81 ; 95 \%$ CI: $1.17-2.79 ; P=0.008$ ) or CSS (multivariable HR: $1.61 ; 95 \%$ CI: $0.89-2.88$; $P=0.111)$.

Other prognostic factors in the multivariable model. The multivariable model confirmed the independent prognostic significance of lymphovascular space invasion for both OS (Table 1) and CSS (Table 2). Age, stage and grade were also significant independent prognostic indicators for both OS and CSS but, as expected, the effect of age was magnified for OS compared with CSS, and vice versa for grade and stage. When different endometrial cancer histopathological subtypes were compared with EEC as the reference group, only a diagnosis of carcinosarcoma associated with worse OS and CSS, confirming the particularly poor outlook associated with this subtype (Amant et al, 2005). A diagnosis of serous or clear cell carcinoma (both de facto grade 3 carcinomas) was not independently predictive, perhaps partly due to the relatively small population sizes of these subgroups and the fact that grade was also included in the model. Similarly, a diagnosis of mixed carcinoma (serous or clear cell combined with endometrioid histology) was not independently predictive, although univariable analysis suggested that the risk of endometrial cancer-related death was lower in this population compared with that of patients diagnosed with pure serous or clear cell tumours (Table 2).

Subgroup analysis of combined NLR and PLR in early and latestage patients. The prognostic value of the combined NLR- and PLR-based stratification system was next investigated in early (I/II) 

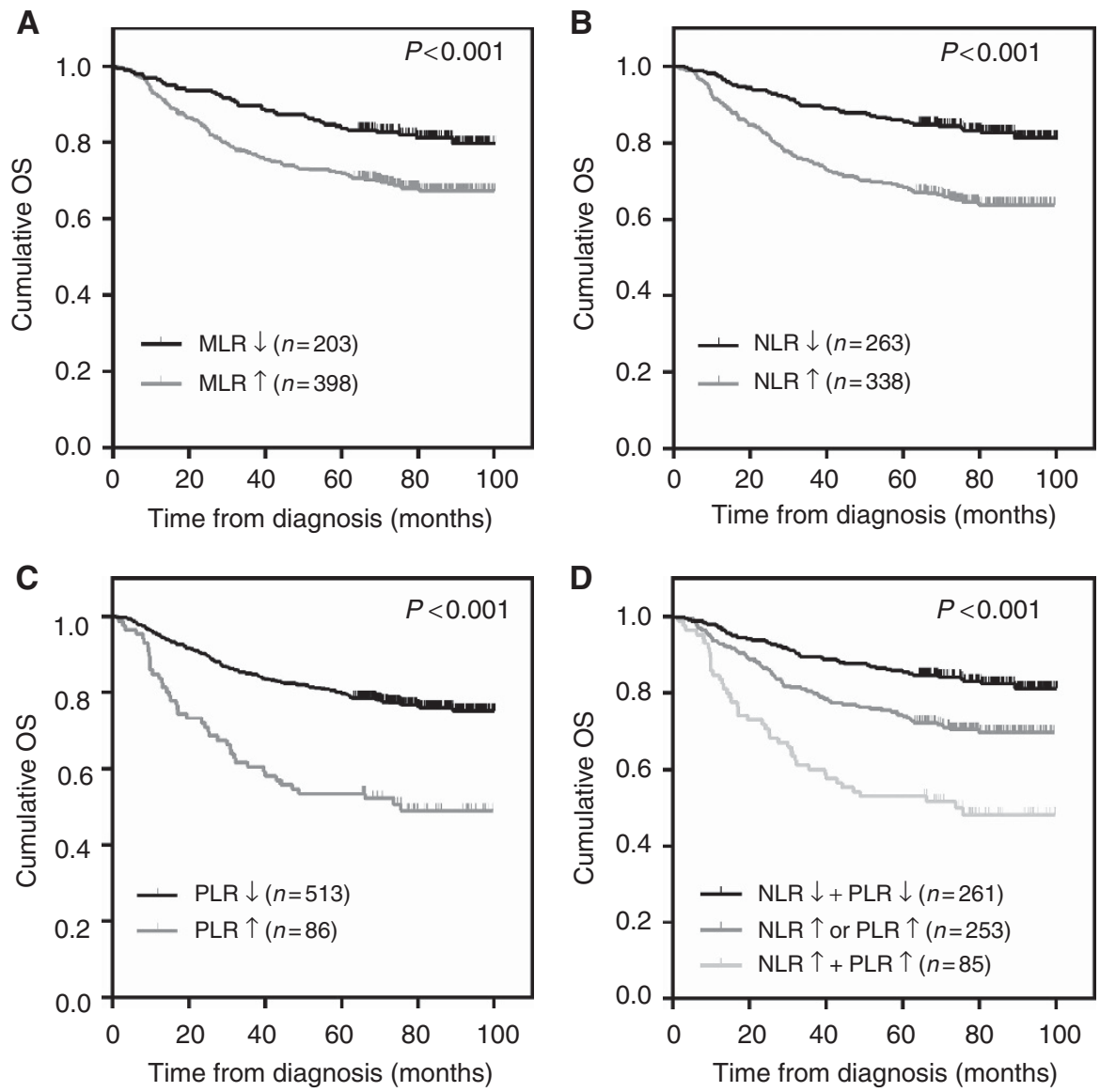

Figure 1. Overall survival of endometrial cancer patients stratified according to MLR, NLR and PLR cut-offs. Kaplan-Meier overall survival (OS) curves plus log-rank $P$-values for patients stratified using a monocyte:lymphocyte ratio (MLR) cut-off of 0.19 (A), a neutrophil:lymphocyte ratio (NLR) cut-off of 2.4 (B and D) and a platelet:lymphocyte ratio (PLR) cut-off of 240 (C and D). High and low ratio values are indicated by $\uparrow$ and $\downarrow$, respectively, applying the cut-offs defined above. The number of patients falling into each category is also indicated.

and late-stage (III/IV) endometrial cancer subgroups (Figure 3). In multivariable analysis, when adjusting for age, grade and lymphovascular space invasion, combined high NLR and high PLR was significantly associated with worse OS and CSS in both early and late-stage subgroups. In the early stage subgroup, the intermediate risk group (with NLR-high or PLR-high status) was significantly associated with worse OS but not CSS (Figure $3 \mathrm{~A}$ and B). By contrast, there was a trend for intermediate risk group to associate with both worse OS and CSS in late-stage patients (Figure 3C and D), although the numbers in the late-stage subgroup were relatively small.

Association of NLR, PLR and MLR with other clinicopathological variables. Potential relationships between NLR, PLR, MLR and other clinicopathological factors were then explored (Table 3). Both NLR and PLR were associated with features of high tumour burden/metastatic potential, including stage (where the association was highly significant; $P<0.001$ ), lymphovascular space invasion and lymph node positivity. Neutrophil:lymphocyte ratio was significantly higher in patients diagnosed with stage IV cancers and PLR was significantly higher in patients with stage IV cancer compared with those with stages I and II. NLR and PLR were both significantly higher in patients diagnosed with lymphovascular space invasion and with lymph node positivity, although the strength of these associations was greater for lymphovascular space invasion. Interestingly, NLR was significantly higher in patients with a diagnosis of carcinosarcoma compared with the EEC group. Both NLR and PLR were significantly associated with age ( $P=0.013$ and 0.035 , respectively). However, neither NLR nor
PLR correlated with age as a continuous variable. By contrast, MLR was highly significantly associated with age $(P<0.001)$ and significantly higher in patients aged $\geqslant 75$ years compared with the groups aged 55-64 and 65-74 years. MLR also correlated weakly, but significantly, with age as a continuous variable (Spearman's rho coefficient $0.129 ; P=0.002$ ). Monocyte:lymphocyte ratio did not associate with any other clinicopathological factor except stage $(P=0.001)$, although this association was less significant than that of NLR or PLR. We also investigated potential associations of NLR, PLR and MLR with Charlson co-morbidity index. However, no significant association was found using either Spearman's rho test on ordinal Charlson index data or by MannWhitney $U$-tests on patient populations dichotomised according to Charlson scores at any cut-off point (data not shown).

\section{DISCUSSION}

This is the largest study to investigate the prognostic role of preoperative NLR and PLR in endometrial cancer, and the only such study to investigate the prognostic potential of MLR in this disease. Both NLR and PLR were identified as having independent prognostic value when adjusted for age, stage, grade, lymphovascular space invasion and histopathological subtype. In this regard, previous studies of these systemic inflammatory markers in endometrial carcinoma have explored the potential of NLR and PLR in the diagnostic setting (Acmaz et al, 2014; Mete Ural et al, 2014), or as predictive markers of nodal metastasis (Suh et al, 

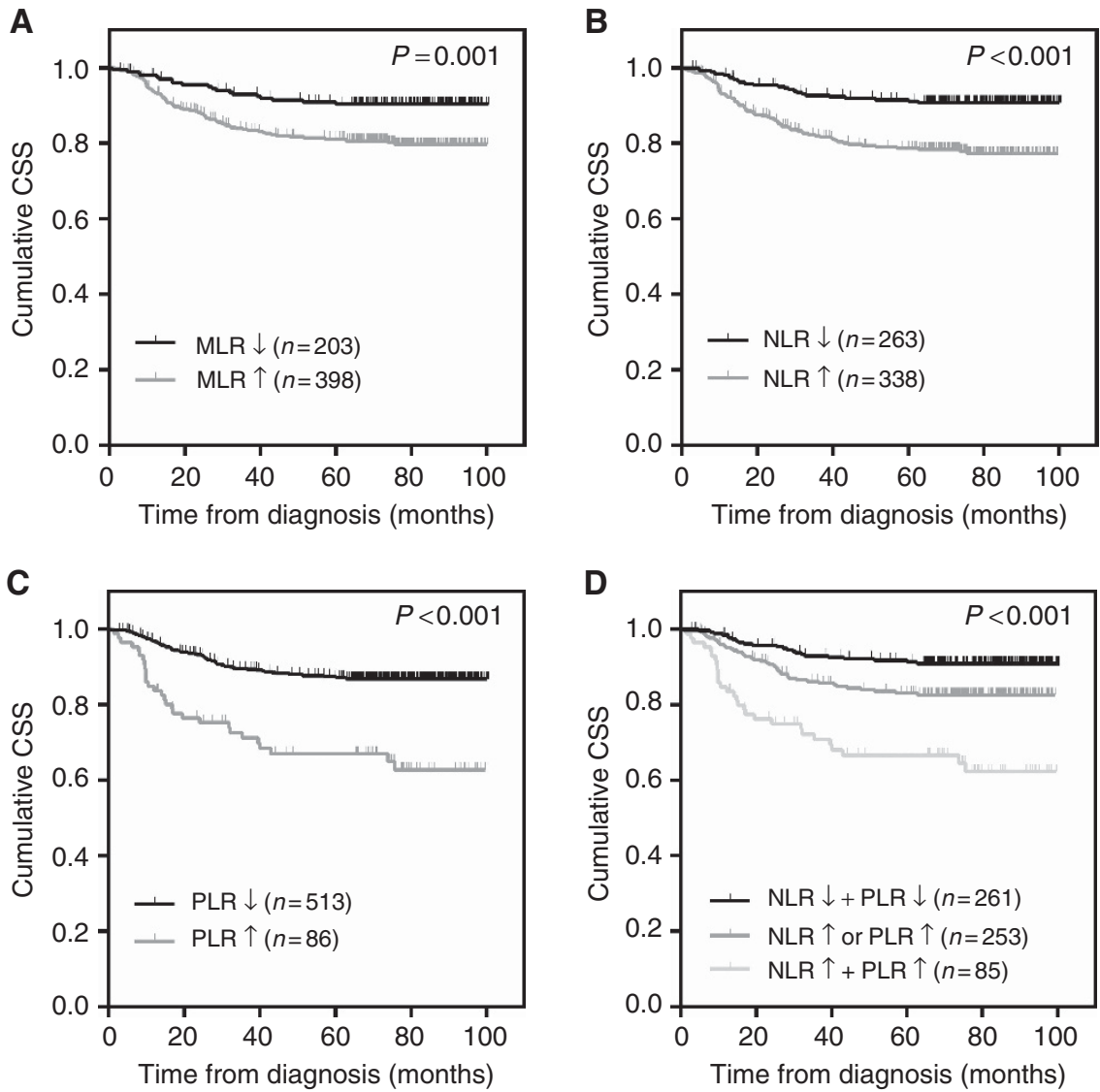

Figure 2. Cancer-specific survival of endometrial cancer patients stratified according to MLR, NLR and PLR cut-offs. Kaplan-Meier cancerspecific survival (CSS) curves plus log-rank $P$-values for patients stratified using a monocyte:lymphocyte ratio (MLR) cut-off of 0.19 (A), a neutrophil:lymphocyte ratio (NLR) cut-off of 2.4 (B and $\mathbf{D}$ ) and a platelet:lymphocyte ratio (PLR) cut-off of 240 ( $\mathbf{C}$ and $\mathbf{D})$. High and low ratio values are indicated by $\uparrow$ and $\downarrow$, respectively, applying the cut-offs defined above. The number of patients falling into each category is also indicated.

2012) and cervical stromal invasion in EEC (Wang et al, 2013). A recent study (Haruma et al, 2015) on a cohort of 320 endometrial cancer patients identified high NLR as having independent adverse prognostic significance for OS. However, no independent prognostic significance was identified for PLR, which was only borderline significant for OS even in univariable analysis. The reasons for the discrepant findings for PLR may be due to the fact that although there was close agreement in optimised NLR cut-offs (2.7 compared with 2.4 defined herein), optimised PLR cut-offs were quite dissimilar (174 as opposed to 240 applied herein). This, in turn, may reflect the smaller cohort size used by Haruma et al (2015) (320 compared with 605 in the present study), leading to sub-optimal PLR cut-off determination. It is worth noting that the PLR cut-off determined in the present study defines a relatively small subset of patients (14\%) as high risk, although this subset was associated with particularly poor outcome.

A wealth of research supports the prognostic value of NLR in solid tumours, as illustrated by a recently published meta-analysis of 100 studies (Templeton et al, 2014a), where the analysis of pooled data showed that high NLR associated with adverse OS, CSS progression-free and disease-free survival, although only $10 \%$ of the studies specifically addressed CSS. Evidence is also mounting for the value of PLR in predicting OS for solid tumours (Templeton et al, 2014b). In this regard, preoperative PLR has been demonstrated to be an independent risk factor for worse OS in pancreatic (Smith et al, 2009), colorectal (Kwon et al, 2012) and ovarian cancers (Asher et al, 2011), and to predict independently both worse OS and CSS in breast cancer (Krenn-Pilko et al, 2014). By contrast, few studies conducted to date have investigated the prognostic potential of MLR in non-haematological malignancies. Nonetheless, a number of recent publications across a range of carcinomas have indicated that low preoperative LMR is independently predictive of poor OS in nasopharyngeal, lung and colon cancers (Li et al, 2013; Hu et al, 2014; Stotz et al, 2014a), CSS in renal and pancreatic cancers (Hutterer et al, 2014; Stotz et al, 2014b) and DFS in breast cancer (Ni et al, 2014).

Although ROC-based cut-off optimisation for MLR enabled the stratification of endometrial cancer patients into high (MLR-high) and low (MLR-low) risk groups in univariable analysis in the present study, both NLR- and PLR-based stratification performed better in this regard. Moreover, MLR was not an independent prognostic factor for either OS or CSS. Koh et al (2014) demonstrated a significant negative association between LMR and older age, which mirrors the highly significant positive association of MLR with patients aged $\geqslant 75$ years identified herein. Indeed, the authors suggested that separately defining LMR thresholds for elderly patients may improve the prognostic accuracy of this marker, albeit at the cost of complicating analyses.

The role of inflammation in carcinogenesis and tumour progression is well established. Existing models purport that the inflammatory tumour microenvironment facilitates the subversion of the host immune response by cancer cells, thereby enabling their escape from immunosurveillance, inhibiting apoptosis, promoting genome instability, angiogenesis, invasion and metastatic spread (Coussens and Werb, 2002). However, the biology underlying the relationships between NLR, PLR and MLR, systemic inflammation and the inflammatory tumour microenvironment remain comparatively poorly understood. Both high PLR and NLR have been 

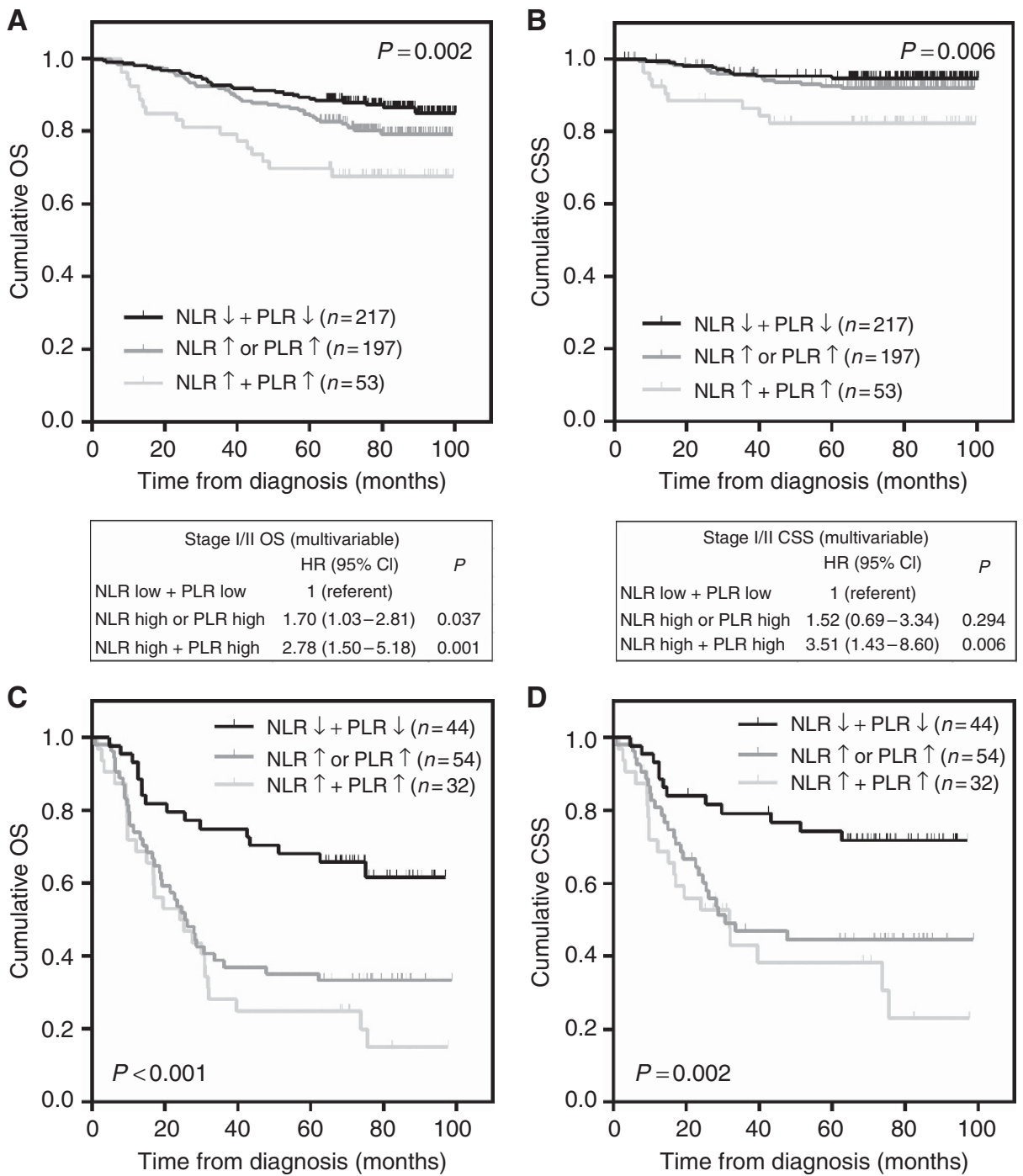

\begin{tabular}{|lcc|}
\hline \multicolumn{3}{|c|}{ Stage III/IV OS (multivariable) } \\
NLR low + PLR low & HR ( $95 \% \mathrm{Cl})$ & $P$ \\
NLR high or PLR high & $1.87(1.00-3.51)$ & 0.050 \\
NLR high + PLR high & $2.48(1.30-4.73)$ & 0.006 \\
\hline
\end{tabular}

\begin{tabular}{|lcc|}
\hline \multicolumn{3}{|c|}{ Stage III/IV CSS (multivariable) } \\
NLR low + PLR low & HR ( $95 \%$ (referent) & $P$ \\
NLR high or PLR high & 1.96 (0.95-4.07) & 0.069 \\
NLR high + PLR high & $2.48(1.30-4.73)$ & 0.021 \\
\hline
\end{tabular}

Figure 3. Survival analysis of combined NLR and PLR-based categorisation in early and late-stage endometrial cancer subgroups. Kaplan-Meier overall survival (OS; $\mathbf{A}$ and $\mathbf{C}$ ) and cancer-specific survival (CSS; $\mathbf{B}$ and $\mathbf{D})$ curves plus log-rank $P$-values in stage I/II (A and $\mathbf{B})$ and stage III/IV (C and D) endometrial cancer patients. High and low ratio values are indicated by $\uparrow$ and $\downarrow$, respectively, applying cut-offs of 2.4 for NLR and 240 for PLR. The number of patients falling into each category is also indicated on the Kaplan-Meier plots. Corresponding multivariable analysis data of combined NLR and PLR-based categorisation adjusted for age, grade and lymphovascular space invasion are tabulated below each plot. $\mathrm{HR}=$ hazard ratio; $\mathrm{Cl}=$ confidence interval.

found to be associated with advanced stage and aggressive disease (Raungkaewmanee et al, 2012; Guthrie et al, 2013a, b; Feng et al, 2014), in line with their highly significant association with advanced stage and the presence of lymphovascular invasion noted in the present study. An emerging link between circulatory cytokines and increased NLR in cancer patients may reflect increased tumour burden/aggressiveness and consequent systemic pro-inflammatory effects, although it is not possible to establish clear causal relationships in these observational studies. Elevated circulatory concentrations of interleukin (IL)-1 receptor antagonist, IL-6, IL-7, IL-8, IL-12, monocyte chemoattractant protein-1 and platelet-derived growth factor-BB were found to be associated with high NLR, while a highly significant association was also found between serum IL- 8 and TNM stage in colorectal cancer
(Kantola et al, 2012). Moreover, Motomura et al (2013) demonstrated an association between elevated serum and peritumoural IL-17, high NLR and increased peritumoural macrophage infiltration in hepatocellular carcinoma patients. In line with this, Guthrie et al (2013b) showed elevated serum IL-6 in colorectal cancer patients to be associated with high NLR and the presence of tumour necrosis, which is both a feature of aggressive disease and an inflammatory trigger. Analogously, Stone et al (2012) provided experimental evidence for the role of IL- 6 release by ovarian cancer cells in stimulating hepatic thrombopoeitin production and paraneoplastic thrombocytosis, which itself stimulates tumour growth and angiogenesis and is a feature of advanced disease and poor outlook in ovarian cancer patients. In this regard, however, PLR proved to be a more sensitive prognostic indicator than 
Table 3. Associations of NLR, PLR and MLR with other clinicopathological factors

\begin{tabular}{|c|c|c|c|c|c|c|c|}
\hline Factor & $n(\%)$ & NLR, Median (IQR) & $P$ & PLR, Median (IQR) & $P$ & MLR, Median (IQR) & $P$ \\
\hline Total & $605(100)$ & $2.56(1.87-3.59)$ & & $144(112-200)$ & & $0.216(0.170-0.293)$ & \\
\hline \multicolumn{8}{|l|}{ Age (years) } \\
\hline $\begin{array}{l}<55 \\
55-64 \\
65-74 \\
\geqslant 75\end{array}$ & $\begin{array}{l}100(16.5) \\
198(32.7) \\
185(30.6) \\
122(20.2)\end{array}$ & $\begin{array}{l}2.66(1.96-3.64)^{\mathrm{a}, \mathrm{b}} \\
2.36(1.71-3.30)^{\mathrm{a}} \\
2.49(1.92-3.43)^{\mathrm{a}, \mathrm{b}} \\
2.91(2.17-3.88)^{\mathrm{b}}\end{array}$ & 0.013 & $\begin{array}{c}142(113-210)^{a, b} \\
134(103-185)^{a} \\
147(112-202)^{a, b} \\
156(120-210)^{b}\end{array}$ & 0.036 & $\begin{array}{l}0.214(0.163-0.296)^{\mathrm{a}, \mathrm{b}} \\
0.204(0.158-0.272)^{\mathrm{a}} \\
0.220(0.175-0.275)^{\mathrm{a}} \\
0.249(0.194-0.354)^{\mathrm{b}}\end{array}$ & $<0.001$ \\
\hline \multicolumn{8}{|l|}{ Stage (FIGO 2009) } \\
\hline $\begin{array}{l}\text { I } \\
\text { II } \\
\text { III } \\
\text { IV } \\
\text { Missing data }\end{array}$ & $\begin{aligned} 414 & (68.4) \\
57 & (9.4) \\
101 & (16.7) \\
31 & (5.1) \\
2 & (0.3)\end{aligned}$ & $\begin{array}{l}2.47(1.79-3.32)^{\mathrm{a}} \\
2.41(1.88-3.73)^{\mathrm{a}} \\
2.81(2.01-4.00)^{\mathrm{a}} \\
3.68(2.75-5.29)^{\mathrm{b}} \\
\quad-\quad\end{array}$ & $<0.001$ & $\begin{array}{c}140(108-192)^{\mathrm{a}} \\
145(86-201)^{\mathrm{a}} \\
156(120-207)^{\mathrm{a}, \mathrm{b}} \\
206(135-285)^{\mathrm{b}} \\
-\end{array}$ & $<0.001$ & $\begin{array}{c}0.214(0.163-0.279)^{\mathrm{a}} \\
0.209(0.179-0.298)^{\mathrm{a}} \\
0.223(0.170-0.304)^{\mathrm{a}} \\
0.300(0.219-0.391)^{\mathrm{b}} \\
-\end{array}$ & 0.001 \\
\hline \multicolumn{8}{|l|}{ Grade } \\
\hline $\begin{array}{l}1 \\
2 \\
3\end{array}$ & $\begin{array}{l}256(42.3) \\
156(25.8) \\
193(31.9)\end{array}$ & $\begin{array}{l}2.46(1.84-3.30) \\
2.45(1.81-3.80) \\
2.77(2.03-3.83)\end{array}$ & 0.055 & $\begin{array}{l}136(106-193) \\
151(115-195) \\
150(115-214)\end{array}$ & 0.131 & $\begin{array}{l}0.214(0.167-0.285) \\
0.214(0.167-0.274) \\
0.221(0.178-0.314)\end{array}$ & 0.272 \\
\hline \multicolumn{8}{|c|}{ Histopathological subtype } \\
\hline $\begin{array}{l}\text { Endometrioid (EEC) } \\
\text { Serous } \\
\text { Clear Cell } \\
\text { Carcinosarcoma } \\
\text { Mixed (EEC + non-EEC) }\end{array}$ & $\begin{aligned} & 468(77.4) \\
& 38(6.3) \\
& 13(2.1) \\
& 29(4.8) \\
& 57(9.4)\end{aligned}$ & $\begin{array}{c}2.48(1.86-3.51)^{\mathrm{a}} \\
2.90(1.83-3.40)^{\mathrm{a}, \mathrm{b}} \\
2.88(2.39-3.20)^{\mathrm{a}, \mathrm{b}} \\
3.15(2.60-5.58)^{\mathrm{b}} \\
2.47(1.78-3.55)^{\mathrm{a}, \mathrm{b}}\end{array}$ & 0.021 & $\begin{array}{l}143(111-195) \\
132(112-199) \\
130(113-229) \\
179(131-258) \\
158(112-208)\end{array}$ & 0.206 & $\begin{array}{l}0.213(0.167-0.281) \\
0.221(0.168-0.360) \\
0.227(0.215-0.278) \\
0.248(0.216-0.339) \\
0.220(0.170-0.305)\end{array}$ & 0.109 \\
\hline \multicolumn{8}{|l|}{ Lymph nodes } \\
\hline $\begin{array}{l}\text { Negative } \\
\text { Positive } \\
\text { No lymphadenectomy } \\
\text { Missing data }\end{array}$ & $\begin{array}{c}356(58.8) \\
70(11.6) \\
168(28.6) \\
6(1.0)\end{array}$ & $\begin{array}{c}2.48(1.80-3.38) \\
2.85(2.18-4.00) \\
- \\
-\end{array}$ & $0.024^{\dagger}$ & $\begin{array}{c}143(109-197) \\
165(121-206) \\
- \\
-\end{array}$ & $0.045^{\dagger}$ & $\begin{array}{c}0.212(0.163-0.279) \\
0.223(0.178-0.329) \\
- \\
-\end{array}$ & $0.050^{\dagger}$ \\
\hline \multicolumn{8}{|c|}{ Lymphovascular space invasion } \\
\hline $\begin{array}{l}\text { Absent } \\
\text { Present } \\
\text { Missing data }\end{array}$ & $\begin{array}{c}346(57.2) \\
248(41.0) \\
11(1.8)\end{array}$ & $\begin{array}{c}2.46(1.80-3.26) \\
2.77(2.05-4.05) \\
-\end{array}$ & $0.002^{\dagger}$ & $\begin{array}{c}138(108-192) \\
154(116-213) \\
-\end{array}$ & $0.006^{\dagger}$ & $\begin{array}{c}0.212(0.165-0.285) \\
0.224(0.178-0.304) \\
-\end{array}$ & $0.104^{\dagger}$ \\
\hline
\end{tabular}

absolute platelet count in our cohort of endometrial cancer patients. Thus far, no studies have investigated links between circulatory cytokines and PLR or MLR/LMR in cancer patients. As we observed strong correlations between NLR, PLR and MLR, it is likely that these are related phenomena that reflect the complex interactions between the host immune system and the inflammatory tumour microenvironment, together with other patientspecific factors such as age, nutritional status and underlying inflammatory conditions (McMillan, 2009; Bhat et al, 2013; Günay et $a l, 2014)$, all of which likely combine to influence patient survival.

Despite their inter-relationships, both NLR and PLR proved to be better prognostic indicators than MLR in endometrial cancer. By combining NLR and PLR scores using the cut-offs defined for the present study's cohort, it was possible to stratify patients into low (NLR-low, PLR-low), intermediate (NLR-high or PLR-high) and high risk (NLR-high, PLR-high) groups. This approach was particularly successful for predicting OS in multivariable models and accentuated the survival difference between the low and high risk groups in CSS. Moreover, subgroup analysis revealed the findings from this stratification method (high $v s$ low risk) to hold true for both early and late-stage subgroups, although differences in the prognostic significance of the intermediate risk group in early and late-stage subgroups were noted. Thus, NLR and PLR are biomarkers of systemic inflammation that only partially overlap in terms of prognostic information, such that they can be combined to provide additional risk stratification for endometrial cancer patients.

Standard therapy for endometrial cancer includes total hysterectomy and bilateral salpingo-oophorectomy. The extent of associated lymph node dissection and adjuvant chemo- or radiotherapy is dependent on tumour type, stage and grade at diagnosis, along with individual patient factors such as age, functional status and the presence of co-morbidities (Dinkelspeil et al, 2013; DeLeon et al, 2014). Although extensive lymph node dissection has been shown to improve prognostication, it is also associated with marked morbidity, while a survival benefit for low risk early stage endometrial cancer patients has not been demonstrated. However, it potentially alters or eliminates the need for adjuvant therapy in high/intermediate risk patients (Burke et al, 2014). Furthermore, endometrial cancer is a heterogeneous disease presenting diagnostic and prognostic difficulties (Geels et al, 2012; Roelofson et al, 2012; Gilks et al, 2013), and while novel genomic classification methods offer much promise in this regard (DeLeon et al, 2014; Murali et al, 2014), they are yet to be implemented clinically. The present data suggest that NLR and PLR may have potential merit as additional prognostic tools to support clinical decision-making in the surgical and adjuvant therapeutic management of endometrial cancer.

The strengths of the current study are its large patient cohort and comparatively long follow-up period. The limitations are its retrospective design, where it is difficult to control for potential confounding factors. As such, it was beyond the scope of this study to investigate potential interactions between systemic inflammatory markers and response to adjuvant therapies. Independent validation of our cut-offs in prospective studies, including clinical trials, is also warranted prior to their implementation. A further limitation is the heterogeneity of tumour types/stages included in this study. Nevertheless, subgroup analysis revealed combined NLR and PLR to have prognostic value in both early and late-stage 
endometrial cancers, independent of other prognostic variables. In contrast to many other studies, we accounted for patient comorbidities, many of which involve underlying systemic inflammation, e.g., coronary heart disease and chronic obstructive pulmonary disease (Bhat et al, 2013; Günay et al, 2014), by compiling Charlson co-morbidity indices for our patient cohort. However, we found no significant association between Charlson score and NLR, PLR, MLR or survival. In this sense, systemic inflammatory markers may provide a simple and more objective alternative to Charlson scores for predicting survival in endometrial cancer patients.

In conclusion, this study highlights the potential of NLR and PLR as additional prognostic tools. These are simple measures which are essentially cost-neutral and which could aid decisionmaking in the clinical management of endometrial cancer patients.

\section{ACKNOWLEDGEMENTS}

We are greatly indebted to Action on Womb Cancer for funding this study.

\section{CONFLICT OF INTEREST}

The authors declare no conflict of interest.

\section{REFERENCES}

Acmaz G, Aksoy H, Unal D, Ozyurt S, Cingillioglu B, Aksoy U, Muderris I (2014) Are neutrophil/lymphocyte and platelet/lymphocyte ratios associated with endometrial precancerous and cancerous lesions in patients with abnormal uterine bleeding? Asian Pac J Cancer Prev 15(4): 1689-1692.

Amant F, Cadron I, Fuso L, Berteloot P, de Jonge E, Jacomen G, Van Robaeys J, Neven P, Moerman P, Vergote I (2005) Endometrial carcinosarcomas have a different prognosis and pattern of spread compared to high-risk epithelial endometrial cancer. Gynecol Oncol 98(2): 274-280.

Asher V, Lee J, Innamaa A, Bali A (2011) Preoperative platelet lymphocyte ratio as an independent prognostic marker in ovarian cancer. Clin Transl Oncol 13(7): 499-503.

Bhat T, Teli S, Rijal J, Bhat H, Raza M, Khoueiry G, Meghani M, Akhtar M, Costantino T (2013) Neutrophil to lymphocyte ratio and cardiovascular diseases: a review. Expert Rev Cardiovasc Ther 11(1): 55-59.

Bokhman JV (1983) Two pathogenetic types of endometrial carcinoma. Gynecol Oncol 15(1): 10-17.

Boruta 2nd DM, Gehrig PA, Groben PA, Bae-Jump V, Boggess JF, Fowler Jr WC, Van Le L (2004) Uterine serous and grade 3 endometrioid carcinomas: is there a survival difference? Cancer 101(10): 2214-2221.

Briët JM, Hollema H, Reesink N, Aalders JG, Mourits MJ, ten Hoor KA, Pras E, Boezen HM, van der Zee AG, Nijman HW (2005) Lymphvascular space involvement: an independent prognostic factor in endometrial cancer. Gynecol Oncol 96(3): 799-804.

Budczies J, Klauschen F, Sinn BV, Györffy B, Schmitt WD, Darb-Esfahani S, Denkert C (2012) Cutoff Finder: a comprehensive and straightforward Web application enabling rapid biomarker cutoff optimization. PLoS One 7(12): e51862.

Burke WM, Orr J, Leitao M, Salom E, Gehrig P, Olawaiye AB, Brewer M, Boruta D, Villella J, Herzog T, Abu Shahin F, Clinical SGO. Practice Endometrial Cancer Working Group, Society of Gynecologic Oncology Clinical Practice Committee (2014) Endometrial cancer: a review and current management strategies: part I. Gynecol Oncol 134(2): 385-392.

Cancer Research UK cancer statistics (2014) http://www.cancerresearchuk.org/ cancer-info/cancerstats/types/uterus/uk-uterine-cancer-statistics.

Charlson ME, Pompei P, Ales KL, MacKenzie CR (1987) A new method of classifying prognostic comorbidity in longitudinal studies: development and validation. J Chronic Dis 40(5): 373-383.
Clarke SJ, Chua W, Moore M, Kao S, Phan V, Tan C, Charles K, McMillan DC (2011) Use of inflammatory markers to guide cancer treatment. Clin Pharmacol Ther 90(3): 475-478.

Coussens LM, Werb Z (2002) Inflammation and cancer. Nature 420(6917): $860-867$.

Creasman W (2009) Revised FIGO staging for carcinoma of the endometrium. Int J Gynaecol Obstet 105(2): 109.

de Jong RA, Nijman HW, Wijbrandi TF, Reyners AK, Boezen HM, Hollema H (2011) Molecular markers and clinical behavior of uterine carcinosarcomas: focus on the epithelial tumor component. Mod Pathol 24(10): 1368-1379.

Dedes KJ, Wetterskog D, Ashworth A, Kaye SB, Reis-Filho JS (2011) Emerging therapeutic targets in endometrial cancer. Nat Rev Clin Oncol 8(5): 261-271.

DeLeon MC, Ammakkanavar NR, Matei D (2014) Adjuvant therapy for endometrial cancer. J Gynecol Oncol 25(2): 136-147.

Dinkelspiel HE, Wright JD, Lewin SN, Herzog TJ (2013) Contemporary clinical management of endometrial cancer. Obstet Gynecol Int 2013: 583891.

Feng JF, Huang Y, Chen QX (2014) Preoperative platelet lymphocyte ratio (PLR) is superior to neutrophil lymphocyte ratio (NLR) as a predictive factor in patients with esophageal squamous cell carcinoma. World J Surg Oncol 12: 58.

Ferlay J, Steliarova-Foucher E, Lortet-Tieulent J, Rosso S, Coebergh JW, Comber H, Forman D, Bray F (2013) Cancer incidence and mortality patterns in Europe: estimates for 40 countries in 2012. Eur J Cancer 49(6): 1374-1403.

Geels YP, Pijnenborg JM, van den Berg-van Erp SH, Bulten J, Visscher DW, Dowdy SC, Massuger LF (2012) Endometrioid endometrial carcinoma with atrophic endometrium and poor prognosis. Obstet Gynecol 120(5): 1124-1131.

Gilks CB, Oliva E, Soslow RA (2013) Poor interobserver reproducibility in the diagnosis of high-grade endometrial carcinoma. Am J Surg Pathol 37(6): 874-881.

Guthrie GJ, Charles KA, Roxburgh CS, Horgan PG, McMillan DC, Clarke SJ (2013a) The systemic inflammation-based neutrophil-lymphocyte ratio: experience in patients with cancer. Crit Rev Oncol Hematol 88(1): 218-230.

Guthrie GJ, Roxburgh CS, Richards CH, Horgan PG, McMillan DC (2013b) Circulating IL-6 concentrations link tumour necrosis and systemic and local inflammatory responses in patients undergoing resection for colorectal cancer. Br J Cancer 109(1): 131-137.

Günay E, Sarınç Ulaşlı S, Akar O, Ahsen A, Günay S, Koyuncu T, Unlü M (2014) Neutrophil-to-lymphocyte ratio in chronic obstructive pulmonary disease: a retrospective study. Inflammation 37(2): 374-380.

Hamilton CA, Cheung MK, Osann K, Chen L, Teng NN, Longacre TA, Powell MA, Hendrickson MR, Kapp DS, Chan JK (2006) Uterine papillary serous and clear cell carcinomas predict for poorer survival compared to grade 3 endometrioid corpus cancers. Br J Cancer 94(5): 642-646.

Haruma T, Nakamura K, Nishida T, Ogawa C, Kusumoto T, Seki N, Hiramatsu Y (2015) Pre-treatment neutrophil to lymphocyte ratio is a predictor of prognosis in endometrial cancer. Anticancer Res 35(1): 337-343.

Hu P, Shen H, Wang G, Zhang P, Liu Q, Du J (2014) Prognostic significance of systemic inflammation-based lymphocyte-monocyte ratio in patients with lung cancer: based on a large cohort study. PLoS One 9(9): e108062.

Hutterer GC, Stoeckigt C, Stojakovic T, Jesche J, Eberhard K, Pummer K, Zigeuner R, Pichler M (2014) Low preoperative lymphocyte-monocyte ratio (LMR) represents a potentially poor prognostic factor in nonmetastatic clear cell renal cell carcinoma. Urol Oncol 32(7): 1041-1048.

Kantola T, Klintrup K, Väyrynen JP, Vornanen J, Bloigu R, Karhu T, Herzig KH, Näpänkangas J, Mäkelä J, Karttunen TJ, Tuomisto A, Mäkinen MJ (2012) Stage-dependent alterations of the serum cytokine pattern in colorectal carcinoma. Br J Cancer 107(10): 1729-1736.

Koh YW, Park CS, Yoon DH, Suh C, Huh J (2014) Should the cut-off values of the lymphocyte to monocyte ratio for prediction of prognosis in diffuse large B-cell lymphoma be changed in elderly patients? Eur J Haematol 93(4): 340-348.

Krenn-Pilko S, Langsenlehner U, Thurner EM, Stojakovic T, Pichler M, Gerger A, Kapp KS, Langsenlehner T (2014) The elevated preoperative platelet-to-lymphocyte ratio predicts poor prognosis in breast cancer patients. Br J Cancer 110(10): 2524-2530.

Kwon HC, Kim SH, Oh SY, Lee S, Lee JH, Choi HJ, Park KJ, Roh MS, Kim SG, Kim HJ, Lee JH (2012) Clinical significance of preoperative neutrophil- 
lymphocyte versus platelet-lymphocyte ratio in patients with operable colorectal cancer. Biomarkers 17(3): 216-222.

Li J, Jiang R, Liu WS, Liu Q, Xu M, Feng QS, Chen LZ, Bei JX, Chen MY, Zeng YX (2013) A large cohort study reveals the association of elevated peripheral blood lymphocyte-to-monocyte ratio with favorable prognosis in nasopharyngeal carcinoma. PLoS One 8(12): e83069.

McCluggage WG (2002) Uterine carcinosarcomas (malignant mixed mullerian tumours) are metaplastic carcinomas. Int J Gynecol Cancer 12(6): 687-690.

McMillan DC (2009) Systemic inflammation, nutritional status and survival in patients with cancer. Curr Opin Clin Nutr Metab Care 12(3): 223-226.

Mete Ural U, Sehitoğlu I, Bayoğlu Tekin Y, Kir Şahin FJ (2014) Neutrophil-tolymphocyte and platelet-to-lymphocyte ratios in patients with endometria hyperplasia and endometrial cancer. Obstet Gynaecol Res 41(3): 445-448.

Motomura T, Shirabe K, Mano Y, Muto J, Toshima T, Umemoto Y, Fukuhara T, Uchiyama H, Ikegami T, Yoshizumi T, Soejima Y, Maehara Y (2013) Neutrophil-lymphocyte ratio reflects hepatocellular carcinoma recurrence after liver transplantation via inflammatory microenvironment. J Hepatol 58(1): 58-64.

Murali R, Soslow RA, Weigelt B (2014) Classification of endometrial carcinoma: more than two types. Lancet Oncol 15(7): e268-e278.

National Cancer Intelligence Network (2013) Outline of Uterine Cancer in the United Kingdom: Incidence, Mortality and Survival.

Newsham AC, Johnston C, Hall G, Leahy MG, Smith AB, Vikram A, Donnelly AM, Velikova G, Selby PJ, Fisher SE (2011) Development of an advanced database for clinical trials integrated with an electronic patient record system. Comput Biol Med 41(8): 575-586.

Ni XJ, Zhang XL, Ou-Yang QW, Qian GW, Wang L, Chen S, Jiang YZ, Zuo WJ, Wu J, Hu X, Shao ZM (2014) An elevated peripheral blood lymphocyte-tomonocyte ratio predicts favorable response and prognosis in locally advanced breast cancer following neoadjuvant chemotherapy. PLoS One 9(11): el11886.

Patsavas K, Woessner J, Gielda B, Rotmensch J, Yordan E, Bitterman P, Guirguis A (2011) Optimal surgical debulking in uterine papillary serous carcinoma affects survival. Gynecol Oncol 121(3): 581-585.

$\mathrm{R}$ Core Team (2014) R: A language and environment for statistical computing. R Foundation for Statistical Computing: Vienna, Austria. http://www.R-project.org/.

Raungkaewmanee S, Tangjitgamol S, Manusirivithaya S, Srijaipracharoen S, Thavaramara T (2012) Platelet to lymphocyte ratio as a prognostic factor for epithelial ovarian cancer. J Gynecol Oncol 23(4): 265-273.

Roelofsen T, van Ham MA, Wiersma van Tilburg JM, Zomer SF, Bol M, Massuger LF, Bulten J (2012) Pure compared with mixed serous endometrial carcinoma: two different entities? Obstet Gynecol 120(6): 1371-1381.

Smith RA, Bosonnet L, Raraty M, Sutton R, Neoptolemos JP, Campbell F, Ghaneh P (2009) Preoperative platelet-lymphocyte ratio is an independent significant prognostic marker in resected pancreatic ductal adenocarcinoma. Am J Surg 197(4): 466-472.
Soslow RA, Bissonnette JP, Wilton A, Ferguson SE, Alektiar KM, Duska LR, Oliva E (2007) Clinicopathologic analysis of 187 high-grade endometrial carcinomas of different histologic subtypes: similar outcomes belie distinctive biologic differences. Am J Surg Pathol 31(7): 979-987.

Stone RL, Nick AM, McNeish IA, Balkwill F, Han HD, Bottsford-Miller J, Rupairmoole R, Armaiz-Pena GN, Pecot CV, Coward J, Deavers MT, Vasquez HG, Urbauer D, Landen CN, Hu W, Gershenson H, Matsuo K, Shahzad MM, King ER, Tekedereli I, Ozpolat B, Ahn EH, Bond VK, Wang R, Drew AF, Gushiken F, Lamkin D, Collins K, DeGeest K, Lutgendorf SK, Chiu W, Lopez-Berestein G, Afshar-Kharghan V, Sood AK (2012) Paraneoplastic thrombocytosis in ovarian cancer. N Engl J Med 366(7): 610-618.

Stotz M, Pichler M, Absenger G, Szkandera J, Arminger F, Schaberl-Moser R, Samonigg H, Stojakovic T, Gerger A (2014a) The preoperative lymphocyte to monocyte ratio predicts clinical outcome in patients with stage III colon cancer. Br J Cancer 110(2): 435-440.

Stotz M, Szkandera J, Stojakovic T, Seidel J, Samonigg H, Kornprat P, Schaberl-Moser R, Seggewies F, Hoefler G, Gerger A, Pichler M (2014b) The lymphocyte to monocyte ratio in peripheral blood represents a novel prognostic marker in patients with pancreatic cancer. Clin Chem Lab Med 53(3): 499-506.

Suh DH, Kim HS, Chung HH, Kim JW, Park NH, Song YS, Kang SB (2012) Pre-operative systemic inflammatory response markers in predicting lymph node metastasis in endometrioid endometrial adenocarcinoma. Eur J Obstet Gynecol Reprod Biol 162(2): 206-210.

Templeton AJ, Ace O, McNamara MG, Al-Mubarak M, Vera-Badillo FE, Hermanns T, Seruga B, Ocaña A, Tannock IF, Amir E (2014b) Prognostic role of platelet to lymphocyte ratio in solid tumors: a systematic review and meta-analysis. Cancer Epidemiol Biomarkers Prev 23(7): 1204-1212.

Templeton AJ, McNamara MG, Śeruga B, Vera-Badillo FE, Aneja P, Ocaña A, Leibowitz-Amit R, Sonpavde G, Knox JJ, Tran B, Tannock IF, Amir E (2014a) Prognostic role of neutrophil-to-lymphocyte ratio in solid tumors: a systematic review and meta-analysis. J Natl Cancer Inst 106(6): dju124.

Voss MA, Ganesan R, Ludeman L, McCarthy K, Gornall R, Schaller G, Wei W, Sundar S (2012) Should grade 3 endometrioid endometrial carcinoma be considered a type 2 cancer-a clinical and pathological evaluation. Gynecol Oncol 124(1): 15-20.

Wang D, Yang JX, Cao DY, Wan XR, Feng FZ, Huang HF, Shen K, Xiang Y (2013) Preoperative neutrophil-lymphocyte and platelet-lymphocyte ratios as independent predictors of cervical stromal involvement in surgically treated endometrioid adenocarcinoma. Onco Targets Ther 6: 211-216.

This work is published under the standard license to publish agreement. After 12 months the work will become freely available and the license terms will switch to a Creative Commons AttributionNonCommercial-Share Alike 4.0 Unported License

Supplementary Information accompanies this paper on British Journal of Cancer website (http://www.nature.com/bjc) 